\title{
War and Dissociation: The Case of Futurist Aesthetics
}

\author{
Konrad Wojnowski \\ Jagiellonian University \\ ul. Urzędnicza 35/14 Kraków, Poland \\ konrad.wojnowski@gmail.com
}

\begin{abstract}
Thanks to their deliberate engagement in state propaganda Italian Futurists deserved a prominent spot in the history of military aesthetics in the 20th century. However, under what looked like an unequivocal expression of support for war, lied a deep philosophical disagreement concerning its existential and epistemological value. The bone of contention concerned the effects of warfare on perception and, consequently, the means of its depiction. The author analyses this intellectual disagreement within the group and focuses, in particular, on its philosophical implications.
\end{abstract}

Futurism. Avant-garde sensibilities. Art and war. Aesthetics of warfare. War and perception.

\section{INTRODUCTION}

Finding an innovative method for depicting war one which would still resonate with general public was crucial for the Futurists in Italy. Shortly after the outbreak of war in 1914, Marinetti insisted that artists should "live the war pictorially" so that they could to produce politically inspiring works of art (Poggi 2009: 322). However, political ambitions aside', they considered war not only as "the only hygiene of the world", as Marinetti famously professed, but also as potential source for complete renewal of culture. Futurists believed that war - fought on dreadnaughts equipped with heavy artillery or on nimble aeroplanes - is something quintessentially modern, offering them a glimpse into the distant future in which humanity would be transformed by science and technology past all recognition. War - both imagined before its outbreak and experienced first-hand - fuelled speculations about changes coming to civilization, because it showed the effects of new technologies on human psyche, monstrously magnified and accelerated. However, despite unanimous acclaim for war among members of the Futurist movement, individual solutions and motivations for engaging in war with chisels, pens, brushes and easels in hand varied significantly. Both in Futurist manifestos and on Futurist paintings warfare sometimes appears as force that strengthens bodies and spirits of the new Man, and sometimes it is celebrated for its destructive and dissociative power that weakens individual subjectivity upon which the bourgeois passé-ist culture is founded.

\section{ELECTRICAL WAR IN POST-SCARCITY}

In Electrical War (1911), a manifesto which reads now more like a fascinating piece of early sciencefiction, Filippo Tomasso Marinetti paints a picture of post-scarcity reality in which 'hunger and poverty have disappeared' while 'twenty-five great syndicates' (...) 'furiously fought over the markets of a superabundant industrial production' (2009[1911]: 103). In this uncanny reality war is not motivated by necessity (to survive) - it becomes a privilege of the wealthy, much like golf or collecting art. Waging wars serves no economic or political purpose, but rather expresses the highest and most noble need of human beings - to "self-actualize" and evolve:

Every intelligence has grown lucid, every instinct
has been brought to its greatest splendor, and
now they clash with each other for a surplus of
pleasure. Because people easily find enough to
eat, they can perfect their lives in numberless
antagonistic exertions. An anarchy of
perfections. No vibration of life is lost, no mental
energy wasted (103).

In this fragment Marinetti - at the time under influence of anarchist philosophy - suggests that transition from scarcity to surplus economy will probably turn the very nature of human conflicts on its head. It will seize to be a struggle for life and death, because physical obliteration of enemies will not be that important due to the overabundance of resources. In a certain sense Marinetti aesthetizes war as an activity that serves no practical 
(economic) purpose. The confrontational style of Futurist writings which transform art practice into war between aesthetic factions (passé-ists, Cubists, etc.) is mirrored by the idea of war as a different kind of art: if Marinetti rejected the escapist idea of l'art pour l'art he would probably happily embrace the notion of la guerre pour la guerre. The famous statement from The Futurist Manifesto - "a roaring automobile that seems to ride on grapeshot-that is more beautiful than the Victory of Samothrace" (Marinetti 2009[1909]: 51) is just one of many evidences of such bizarre logic. Praising beauty of machines simply means that armored trains, tanks, fighter planes, or even surprising tactics on the battlefield can be considered new art forms, media, or artistic performances. In other words, Marinetti radicalizes the ancient concept of "art of war" (Sun Tzu's book was available to European readers through French translation from 1772) to announce the absolute aesthetization of conflicti".

Even if these speculations seem outlandish and far-out, at least given their historical contextiii, they were actually fueled by serious philosophical conundrum: how to envision the future of human evolution - understood in line with popular reading of Darwin's theory as survival of the fittest - in a reality where there is nothing to compete for, at least in terms of resources necessary for physical well-being. If one considers evolution to be a natural imperative, then it becomes important to ask what will happen without environmental pressure determining objectives of the evolutionary game. Marinetti explicitly challenges the idea of a peaceful end to history in one of his most controversial essays War, the only hygiene of the world:

\begin{abstract}
The latter, denying the infinite principle of human evolution, brings its forward-looking viewpoint to a halt in the ideal of universal peace, a stupid paradise of people caressing in open fields or beneath billowing palm trees (2009 [1911: 84).
\end{abstract}

From this standpoint Marinetti's weird divination seems to deal with an issue far more complex and important than only the future of warfare itself. It is not a boyish fantasy, but an opaque forecast into the future of civilization which makes war its modus operandi. Such reading of Marinetti's intentions is in line with many remarks scattered throughout the text. For example, in the first part of the manifesto Marinetti suggests that electricity and communication networks bring together all forms of matter that change states and move according to the rules of war. Cables and wireless technologies create an intelligent planetary super-organism that serves also as (immanent) training grounds for the planetary conflict:
Penetrating into every muscle, artery, and nerve of the peninsula, the energy of distant winds and the rebellions of the sea have been transformed by man's genius into many millions of kilowatts, spreading everywhere yet needing no wires, their fecundity governed by the control panels, like keyboards, throbbing under the fingers of the engineers (2009 [1911]: 135).

Working side by side, engineers, mathematicians, and soldiers (gamers), mobilize matter and energy to transform it into information, later distributed worldwide through cables and radio so that "free human intelligence reigns everywhere". This idea of the planet transformed by new communication technologies, expressed even before Édouard Le Roy who introduced the notion of noosphere in 1922, was key to Marinetti's philosophical system. He kept returning to it even 20 years later, for example, in manifesto La Radia, written together with Pino Masnata (1933). In it they speculated about the transformatory potential of electricity and wireless communication and concluded that these technologies must eventually create a virtual environment of unprecedented character. They called it "radia", the artform of the future, and "a pure organism of radiophonic sensations" which would contribute to an "immense enlargement of space" (2009 [1933]: 294). Their idea of "radia" had little to do with the technical device they could know - a centralized broadcasting system critical to the existence of fascist state. Rather, they spoke of a technology which never came into being. Futurist radia bears more resemblance to wireless internet, in which communication patterns emerge spontaneously (bottom-up) and interfere with each other, than old-fashioned radio which only streams sound unidirectionally. As Marinetti and Masnata postulated, in the "hybrid" reality created by wireless technology one will not be able to differentiate between the scene and the audience. In the ecosystem created by radia communication takes place as "struggle of noises". Any discernible sender or receiver disappears in favor of an intelligent process which governs itself through conflicts and collisions. Radia is not a utopian technical device or a new genre of art; it is a (virtual) network environment that can be aptly described using a short passage from Tiziana Terranova's book about digital culture in the age of internet: "characterized by an unprecedented abundance of informational output and by an acceleration of informational dynamics" (2004: 1).

What makes Marinetti's intuitions about "wireless intelligence" even more bold and fascinating is the fact that they were initially drafted even before the outbreak of the $1^{\text {st }}$ World War (1911) when radios were first used on the battlefield. Hence, they should not be considered as aesthetic responses to the new reality of conflict. Rather, as I would like to argue, their significance lies in the extraordinary 
ability to anticipate epistemological transformations that became clearly visible and widely discussed only decades later. One example of such correspondences bending our intuitive notions of linear time can be established between Marinetti's concept of "electrical war" and the notion of "mechanosphere" formulated by Manuel DeLanda in War in the Age of Intelligent Machines, book published exactly 80 years later:

\begin{abstract}
[T]the portion of the "mechanosphere" constituted by computer networks, once it has crossed a certain critical point of connectivity, begins to be inhabited by symmetry-breaking singularities, which give rise to emergent properties in the system. These systems "can encourage the development of intelligent [software] objects, but there is also a sense in which the systems themselves will become intelligent."
\end{abstract}

Similarly to Marinetti, DeLanda argues that the introduction of new weaponry and communication technologies constituted a profound historical shift in the very essence of relations between humans and machines. According to the American philosopher, these new devices, developed and introduced in the name of efficiency and strategic advantage over less technologically developed opponents, inescapably strip human agents from their autonomy and control. This leads to a paradoxical situation: not only the means of conflict change drastically, but also roles and positions of human subjects who wage these wars. The new (hybrid) battlefield populated by artificial agents, performing crucial tasks on every level of command and execution, organizes itself spontaneously, just like a turbulent fluid, oscillating between momentary states of order and disorder. The old metaphors of battlefield - such as board games like chess or go - become obsolete in the modern age, because it is impossible to find individuals or institutions which meets the criteria of independent decision-maker. To think of war in terms of chess makes sense only inasmuch the theatre of war can be abstracted from its environment. Much like DeLanda, an enthusiastic reader of Deleuze and Guattari's philosophy, Futurists recognized this epistemic shift being drawn to technology and its dehumanizing potential. Both DeLanda and Marinetti's bunch strongly believed that modern technology is capable of disintegrating the individual subjectivity, the most important anchor of passéist culture.

\section{A DIFFERENT WAR (FOR PROPAGANDIST USE ONLY)}

Ideas expressed by Marinetti in Electrical War tell only the half of the story concerning Futurist aesthetics of war. When Marinetti was confronted with political reality in 1914 - and for strategic reasons opted for a politically beneficial aesthetic program - he restrained his vision. In a letter sent to Gino Severini in November 1914 he favored art that glorifies machines as well as lionhearted soldiers who operate them:

It would be best to aim for some kind of extended expression, not only for the tastes of a small group of connoisseurs; an expression so intense and synthetic that will resonate with imagination of all, or almost all, intelligent viewers (...). Your paintings and sketches should be less abstract, or even more realistic, a bit like advanced form of postimpressionism (in Strożek 2015: 120).

Severini reacted to Marinetti's advice by painting Armored Train in Action in 1915 which presented war as glorious and sublime activity. Out of step with Futurist aesthetic program Severini depicted the train as an object which imposes its rigid materiality upon its environment. The juxtaposition of triumphant technology and subordinate nature cannot be more apparent ${ }^{\mathrm{iv}}$.

Obviously, Marinetti's advice (and its manifestation in Severini's painting) stood in stark contrast to his own aesthetico-philosophical considerations as well as official declarations of futurist painters who publicly celebrated psychic disorientation, disintegration of objecthood on canvas, and nondualist ontologies inspired by thermodynamics or theory of general relativity. Marinetti was well aware of this blasphemy and probably for that reason kept his advice private. This double game reveals an important epistemological rupture within the futurist movement: between political pragmatism which soon resulted in an alliance with Benito Mussolini on the one side, and free aesthetic speculation which initially motivated the group on the other. Marinetti and his bunch were drawn to the destructive and transformatory potential of war, while the state wanted to mobilize its citizens by presenting it as a sublime event unifying the people towards a common cause.

Moreover, it is actually very difficult to pin point Marinetti's precise views on the function and psychic effects of war, because he tended to oscillate from one philosophical position to another, sometimes even within the same text. For example, in manifesto Destruction of Syntax - Wireless Imagination - Words-in-Freedom he professes "[m]ultiple and simultaneous states of mind within the same individual" as anchors of Futurist sensibility and goes on to praise war as "sanguinary and necessary test of the strength of a people" (Marinetti 2009 [1913]: 144). Obviously, both beliefs - affirmation of identity disorders and of psyche strengthened in combat - were mutually exclusive. In the same manner Marinetti's war aesthetics wavered between early radical experiments, like Simultaneous Poetry of Woven 
Light or Bombardment, and far more conservative poems written during $2^{\text {nd }}$ World War to praise the glory of Italian special forces.

\section{WAR AND DISSOCIATION}

Given that Futurist's intellectual fascination with war was contradictory to more simplistic demands of military propaganda, it should come as no surprise that finding a "truly" Futurist depiction of war is not so simple. If we consider Marinetti's Electrical War as the program-manifesto, only one example comes to mind in this regard - a painting by Umberto Boccioni, finished in the same year as Severini's Train - The Charge of the Lancers. To some extant Boccioni's painting not only presents warfare as a dissociative force, but also illustrates the aforementioned contradiction between philosophical and propagandist Futurism. Being a collage, the work juxtaposes two representations of war: a press report in a daily newspaper, and a highly dynamic and seemingly abstract depiction of an unidentified battle scene. The newspaper, used by Boccioni as canvas, obviously connotes the state propaganda and hints at a broader, political dimension of military conflict, whereas the scene in the middle of the painting can be interpreted as a visual representation of a military phase-shift: objects and living beings dissolving to form indeterminate fields of intensity. The scene was painted in a manner typical for Boccioni's style and in accord with his philosophical conviction that the painter should achieve "decomposition of the object" to unleash "[t]he plastic potential that resides" within it. This aesthetic proposition was motivated both by an ontological assumption that movement of energy precedes objecthood of matter (borrowed from Henri Bergson) and an epistemological theorem that stability and concreteness of objects is, in fact, only an illusion stemming from imperfection of human senses (Boccioni 2016 [1914]).

To support his critical view of perspective in painting, Boccioni often made references in this writings to examples taken from popular science books: concepts like X-rays, Hertzian waves, electrons and 'the electric theory of matter'. All these citations were carefully selected to support the Futurist image of the world: as ever-changing, unstable, uncertain, and lacking a privileged frame of reference. For Boccioni grasping reality in its elusiveness and lability was no easy task, but a long processes of alienating oneself from a fixed sense of self, also through scientific objectivism (see also Daston, Galison 2007: 36). The greyish swarm of matter, described in the title as "lancers", is neither an assemblage of objects, nor an object seen from multiple perspectives. It is rather an elusive phenomenon which exists beyond the duality of concreteness and abstractness: it is movement, both actual and virtual, that expresses "plastic potentiality" of swarming matter. It is an image of war as a force for deindividuation which is not only to be understood psychologically, but also materialistically. In other words, if Severini's painting praises the metallic grandeur of war, Boccioni praises the dissolution of men into energy. In his depiction of a galloping cavalry unit there are no discernible figures of horses or people, but only abstract movements of energies which can be artificially assigned roles or meanings by the state apparatus (through commands) and the press (through reporting). In this sense Boccioni, who paints bodies as intensities, aestheticizes the epistemic shift in understanding matter that took place in the previous century - from mechanics to thermodynamics. Bruce Clarke summarizes this transition as follows:

With the emergence of thermodynamics in the mid-nineteenth century, physical attention was enlarged from vectoral forces to scalar energies, quantities described by their magnitude irrespective of their motions. In thermodynamics, the perceptible trajectories of singular bodies planets and projectiles - give way to the quantifiable intensities of molecular populations, and the motions defined by classical mechanics become relative to the averaged behaviors of thermodynamic ensembles (2002: 19).

It is also worth noticing that this transition - from mechanics to thermodynamics - also took place decades later in the military which now heavily relies on thermal vision and thermal imaging. Infrared vision is now used primarily in military equipment and its use outside of the battlefield is rare.

Another example of a non-propagandist Futurist artwork about war comes from Marinetti himself who in a poem, sent to Luigi Russolo and written just after he arrived on the battlefront. Also in this case war is presented as a powerful dissociative force that rids of human subjectivity and alters the senses. In this piece, written before the full awakening of his political ambitions, one he depicts a scene stitched together from fragments of multiple points view:

Debris of echos in this theater of laying rivers sitting villages standing mounts recognized

in the audience Maritza Tungia Rodopes 1st and 2d

rows loggias groundfloor boxes 2,000 shrapnels gesticulation

explosion zang-toumb white handkerchiefs full of gold toumbtoumb

clouds-gallery 2,000 grenades thundering applause Quick 
quick such enthusiasm pulling hair very black hairs ZANGTOUMB-

TOUMB war noises orchestra blown beneath a note

of silence hanging in full sky captive golden balloon controlling the fire (Russolo 2009 [1913]: 136).

To get rid of the lyrical subject, or even any sign of personal taste, Marinetti looks at the battlefield from an aerial perspective - uncanny for most people at that time - throws in a bit of statistics taken from a supply management list, a few onomatopoeias, a close-up from the trenches, and on top of that he introduces an entity from a different space-time - mountains figuring as theatre audience.

It is most probable that the language and the imaginary of Marinetti's poem was crucially shaped by a sense of novelty of this experience which left him disturbed and agitated. Awe and amazement with these unknown sounds, images, and events happening within a familiar frame of a mountain landscape lead him to perceive the battlefront as something unreal and uncanny. In this regard his attempt at depicting war can be compared to that of Ernst Jünger's in Storm of Steel, in which the German author notes that shortly after arriving at the frontline he found pleasure in the aestheticomilitary spectacle. As he recalls, he completely immersed himself in the distant sounds of artillery which made him dissociate from reality. Jünger who wrote about the event with the benefit of hindsight explained that as he was not able to locate exact sources of potentially lethal noises, he perceived them "as distant and peculiar (...), as events on another planet". He felt "indifferent" by shells "crisscrossing apparently aimlessly over the little warren of trenches where a few of us were holed up". However, Jünger also self-consciously observed that his reaction was probably caused by the sheer novelty of his experience. He remarked that, as he matured as a soldier and learned to discern sounds and associate them with specific events in space, he became capable of situating himself as an anxious individual trembling in relation to metal objects flying above his head. In other words, he grew out of his role of a captivated spectator lost in the military spectacle to become a simple soldier struggling to keep his individual life.

\section{CONCLUSION}

In sum, while Marinetti became later convinced that futurist art should glorify war and present its invigorating effects, he was more initially drawn, like his friend Boccioni, to the psychic effects of war experience, particularly, its dissociative influence on the ego. Moreover, war was the most obvious and distinct example of a strictly futurist event: loaded with heavy machinery, dangerous, and inhumanly fast. Thereby it allowed them to root their avant-garde, experimental form in an experience that could have been shared by numerous people. As both artists denigrated the aesthetics and epistemology of static realismfounded on the illusion of concentrated "I"--they were eventually confronted with the reality of political expectations and common familiarization of experience. If at first the Futurists believed war to be a Dionysian (excessive and transformatory) process resulting in re- to be played continuously for its own sake - eventually they had retreat on more conservative positions. Their fascinating and visionary ideas proved useless from the political perspective and - on top of that - did not resonate well with those who experienced the frightening boredom of trench warfare. However, they are worth revisiting in the $21^{\text {st }}$ century, particularly in the often-discussed context of hybrid warfare, whose aim is not to win with the opponent, but to use every resource and strategy only to produce uncertainty within its ranks. Just like avant-garde art, hybrid war can be fought infinitely without any side emerging victorious, but - contrary to Marinetti's intuition - it seems doubtful if this process can lead to "an anarchy of perfections".

\section{REFERENCES}

Benjamin, W. (2008 [1936]). The Work of Art in the Age of Its Technological Reproducibility. In Jennings M. W., Doherty B., Levin T. Y. (eds.), Work of Art in the Age of Its Technological Reproducibility, and Other Writings on Media. Harvard University Press, Cambridge.

Boccioni, U. (2016 [1914]). Futurist Painting Sculpture. Getty Research Institute, Los Angeles.

Clark, B. (2002). From Thermodynamics to Virtuality. In Clarke B., Henderson L.D., From Energy to Information: Representation in Science and Technology, Art, and Literature. Stanford University Press, Stanford.

Dalton, L. Galison, P. (2007). Objectivity. Zone Books, New York.

DeLanda, M. (1991) War in the Age of Intelligent Machines. Zone Books, New York.

Marinetti, F.T. (2009 [1909]). The Founding and Manifesto of Futurism. In Rainey L., Poggi C., Wittman L. (eds.), Futurism: An Anthology. Yale University Press, New Haven.

Marinetti, F.T. (2009 [1911]). Electrical War. In Rainey L., Poggi C., Wittman L. (eds.), Futurism: An Anthology. Yale University Press, New Haven. 
